\title{
THE WORDS OF AGRIPPA TO ST PAUL
}

At the end of his critical note on Acts xxy 28 , after suggesting that

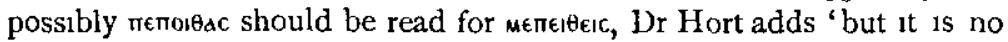
less possible that the error lies elsewhere' These words invite suggestions

Now any one who reads through the seventeenth, exghteenth, and nineteenth books of the Antrquitzes of Josephus can hardly farl to be

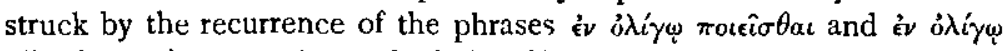

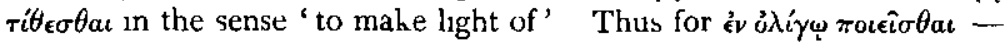

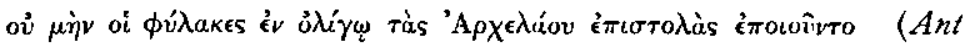
xvil 223)

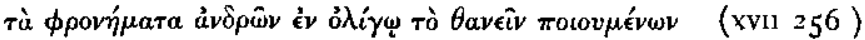

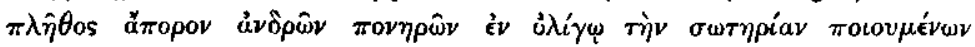

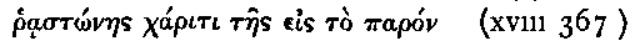

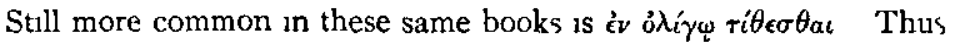

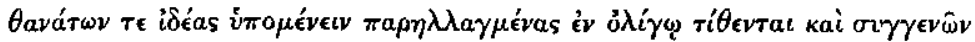

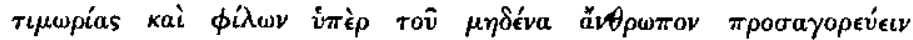
$\delta \epsilon \sigma \pi o ́ \tau \eta v . \quad(x \vee 11123)$

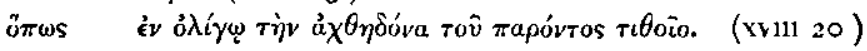

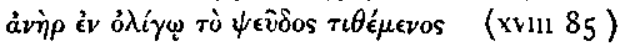

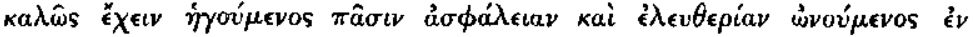

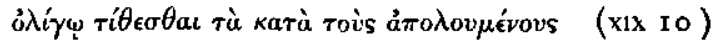

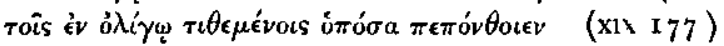

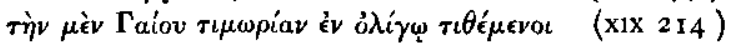

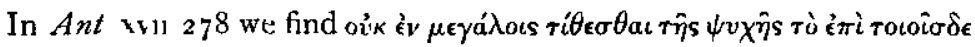

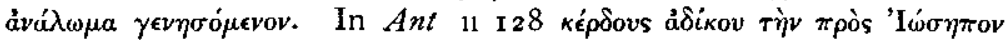

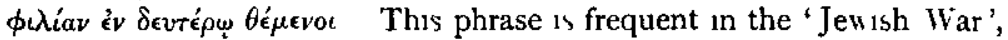

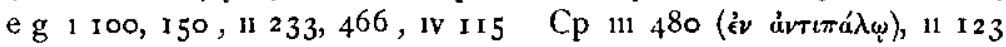
and $146(\dot{\epsilon} v \kappa a \lambda \hat{\omega})$.

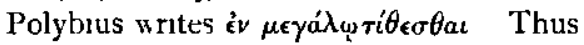

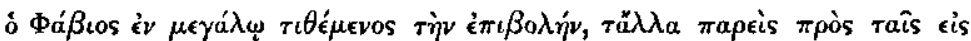

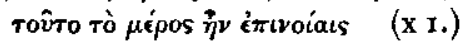

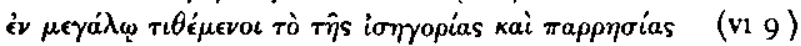

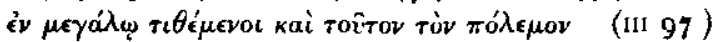

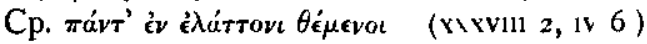


One other passage of Polybius may be quoted to shew how in such

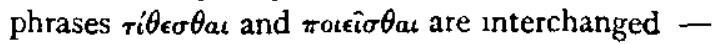

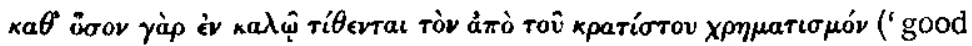

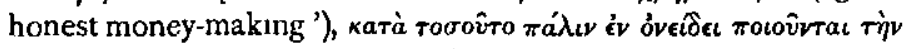

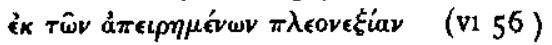

If now we turn to Agrippa's words, the suspicion is irresistible that

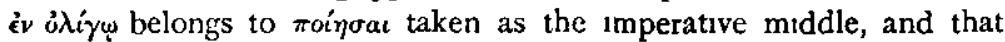
St Luke wrote $\pi \epsilon^{i} \theta \epsilon$ Agrippa has come in great state to enjoy an

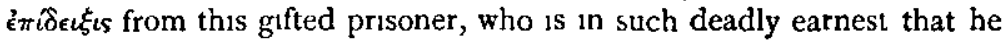
is spoiling it all Festus has burst out with 'You are mad' Agrippa suggests that St Paul should not trouble himself about winning him as a convert to Christianity Let that be quite a subordinate consuderation, he urges They are there to be entertained, and possibly to get material for a favourable report to the Emperor 'Pray regard winning me for a Christian as a matter of little moment'

I have not found $\pi \epsilon^{i} \theta_{\epsilon} \iota v$ with a proleptic accusative to express its result But such an accusative after $\delta \iota \delta a ́ \sigma \kappa \epsilon t v$ is fairly familiar, and $\pi \epsilon i \theta \epsilon \iota v$ кai $\delta \iota \delta \alpha \sigma \kappa \epsilon \nu$ is a frequent collocation in Plutarch (e g 1 I6 r B,

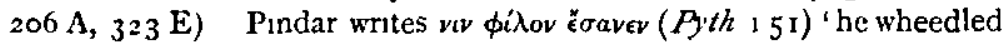
him into friendship' And Josephus has

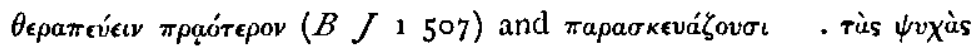
a $\lambda$ кírous ( $B J$ ill 102 )

St Paul's reply is to the $\epsilon$ ffect that the conversion of Agrippa and all his hearers is to him a wholly adequate object Whether God be using him that day only to cffect that conversion or be pleased to make it sub. ordinate to some yet higher purpose, $\mathrm{H}$ is servant will be equally satisfied It is not for hum to say what is primary and what is secondary with God

G H WHITIKER. 